\title{
Efeitos de Testes de Leitura sobre a Generalização em Crianças em Processo de Alfabetização
}

\author{
JoséGonçalves Medeiros ${ }^{1}$ \\ Universidade Federal de Santa Catarina \\ Rosária Maria Fernandes da Silva \\ Fundação Universidade do Vale do Itajaí
}

\begin{abstract}
Resumo
O presente estudo, de aquisição de leitura e escrita e fundamentado nos estudos de equivalência de estímulos, foi realizado com 7 crianças entre 7 e 16 anos, em processo de alfabetização, visando a investigação dos efeitos de testes de leitura, apresentados durante as etapas de um procedimento de escolha de acordo com o modelo. Dois conjuntos de testes de leitura foram apresentados durante as etapas dos pré e pós-testes e da aprendizagem. Todos os participantes aprenderam as palavras ensinadas, porém, apenas 4 deles generalizaram. Os testes de leitura não produziram generalização diferencial entre os grupos. Tendo por referência uma análise funcional e estrutural das palavras utilizadas, os acertos são discutidos com base nos efeitos da recombinação silábica e da contigüidade temporal entre tentativas reforçadas e não reforçadas; os erros são atribuídos à natureza abstrata das palavras de generalização, propondo-se, para os testes, o uso de palavras do cotidiano dos participantes. Palavras-chave: Equivalência de estímulos; escolha de acordo com o modelo; fracasso escolar; testes de leitura.
\end{abstract}

\section{The Purposes of Reading Tests over Generalization in Teaching of Reading to Children}

\begin{abstract}
The present study aimed at investigating reading and writing acquisition, based on studies on stimulus equivalence. It was carried out with 7 children ranging from 7 to 16 years old, during literacy development, with the specific objective of investigating the effects of reading tests presented during the phases of a matching procedure. Two sets of reading tests were used during the phases of pre and post-tests and of learning. All participants involved in the research learned the taught words, although only 4 were able to generalize them. The reading tests did not produce differential generalization within the groups. Based on a functional and structural analysis of the words used, the successes are discussed taking into account the effects of the syllabic recombination and of the temporal contiguity with reinforced and non-reinforced attempts; the errors are attributed to the abstract nature of the generalization words, suggesting, for the tests, the use of words belonging to the participants' everyday vocabulary.

Keywords: Stimulus equivalence; matching to sample; school failure; reading tests.
\end{abstract}

O presente artigo está voltado para a área da aprendizagem quelida com a aquisição do comportamento verbal de leitura e escrita (Skinner, 1957/1974) e se fundamenta nos dados obtidos nos estudos de equivalência de estímulos (Barros, 1996; Dixon, 1977; Hübner, 1997; de Rose, 1993; Sidman, 1971; Sidman \& Tailby, 1982; Souza \& de Rose, 1997). Em 1971, Sidman deu início a uma série de investigações em aquisição deleitura e escrita, inaugurando uma nova área de pesquisa que, posteriormente, ficou conhecida como equivalência de estímulos (Aiello, 1995; Matos \& Hübner, 1997; Medeiros, Antonakopoulu, Amorim \& Righetto, 1997a; Medeiros, Monteiro \& Silva, 1997b; Melchiori, Souza \& deRose, 1992; d'Oliveira, 1990; d'Oliveira \& Matos, 1993; Sidman \& Cresson, 1973). No diagrama do estudo de Sidman (ver Figura 1), realizado com adolescentes com deficiência mental, a seta contínua

\footnotetext{
${ }^{1}$ Endereço para correspondência: Caixa Postal 5060, 88040-970, Florianópolis, SC. Fones: (48) 331-9457/ 9283/ 9330. E-mail: medeiros@mbox1.ufsc.br
}

grossa (BD) representa relações de pareamento que os Ps já dominavam antes do início do experimento, ou seja, eram capazes de nomear as figuras que lhes foram apresentadas. As setas contínuas finas representam relações quelhesforam ensinadas: a seta $\mathrm{AB}$ indica que foram capazes de, frente a palavras ditadas, escolher as figuras correspondentes ea seta AC indica que foram capazes de selecionar uma palavra impressa frente a uma palavra ditada. As setas tracejadas indicam que, em decorrência do ensino, os adolescentes foram capazes de emparelhar palavras impressas com suas respectivas figuras (CB) e a emparelhar figuras com seus respectivos nomes (BC) e a ler oralmente (CD).

Os resultados obtidos por Sidman² sugerem que se uma pessoa aprende, através do procedimento de discriminação condicional, as relações entrepalavra falada e figura (AB),

\footnotetext{
2 Para Sidman (1994), equivalência é produto de contingências de quatro termos. Nesse tipo de contingência, a relação de três termos é colocada sob controle condicional ou textual. Dessa forma, o estímulo condicional determina o controle que outro estímulo (estímulo discriminativo) exercerá sobre a resposta.
} 
entre palavra falada e palavra impressa (AC), as relações CB (entre palavra impressa e figura), BC (entre figura e palavra impressa) eCD (entre palavra impressa e palavra falada pelo participante [P]) podem emergir sem que elas tenham sido diretamente ensinadas. Nesse sentido, 0 paradigma de equivalência de estímulos ${ }^{2}$ tem sido bastante utilizado, à medida que oferece bases para uma análise comportamental de comportamentos emergentes (Mackay, 1985; Sidman, 1990).

A pesquisa (Silva, Medeiros \& Souza, 2001), que deu origem a este artigo, diferenciou-se em relação às demais pelo fato de que testes deleitura foram inseridos em todas as etapas do procedimento (pré, pós-teste e aprendizagem ${ }^{3}$ ). A pergunta, portanto, a ser respondida por este estudo é: a presença de tentativas não reforçadas, apresentadas entre tentativas reforçadas, durante a etapa de aprendizagem,

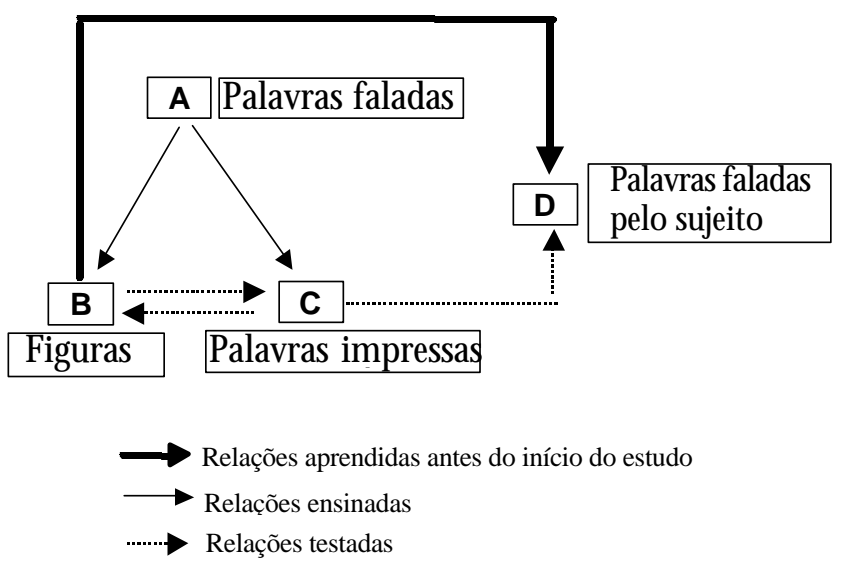

Figura 1. Diagrama do experimento realizado por Sidman (1971).

\footnotetext{
${ }^{2}$ As comunidades verbais estabelecem correspondências entre palavras e eventos. As correspondências operam em ambas as direções, como nas classes de equivalência. "Considere-se, por exemplo, a chuva como estímulo (a visão ou o som dela caindo, ou a sensação da chuva sobre a pele), as respostas ocasionadas pela chuva (como sair com um guarda-chuva, vestir um capote, procurar um refúgio ou apenas divertir-se com ela) e a palavra dhuva. Tanto a palavra chuva como a própria chuva como estímulos podem ocasionar ora uma resposta verbal, a palavra chuva, ou a resposta não verbal apropriada diante da chuva. Podemos olhar por uma janela, ver a chuva e pegar um guarda-chuva para sair de casa; essa resposta, contudo, pode também ser desencadeada por um estímulo verbal, como a informação das condições meteorológicas na televisão. Ao vermos a chuva ou ao ouvirmos a previsão do tempo, podemos telefonar para alguém que trabalhe em um escritório sem janelas e informá-lo sobre as condições do tempo" (Catania, pp. 284-285). No exemplo, tanto a chuva como a palavra chuva (auditiva ou visual) são equivalentes entre si, podendo ocasionar a mesma resposta, isto é, pegar um guarda-chuva.

${ }^{3}$ Refere-se à etapa onde as palavras são ensinadas pela exclusão de uma palavra anteriormente ensinada. $\mathrm{O}$ mais comum é denominar esta etapa de exclusão.
}

facilitaria a emergência denovas classes de respostas (leitura generalizada)? Entre os artigos sobre equivalência de estímulos, não se encontrou nenhum que trabalhasse com um procedimento semelhantea este. Nos estudos realizados nessa área (Aiello, 1995; Matos \& Hübner, 1997; Melchiori \& cols., 1992; d'Oliveira, 1990; d'Oliveira \& Matos, 1993; Sidman \& Cresson, 1973), os testes deleitura são, geralmente, apresentados nos pré e pós-testes, com exceção do trabalho de Souza ede Rose (1997), em que os testes deleitura foram, também, apresentados na equivalência.

Há, como pode ser visto, uma lacuna no conhecimento quanto aos efeitos de testes deleitura sobre a emergência de novas classes de respostas e, também, sobre o responder positivamente conseqüenciado, quando esses testes são apresentados durante a etapa de exclusão ou de aprendizagem. Do ponto de vista dos benefícios para os Ps, ou seja, da relevância social da pesquisa, testes com essa característicanão seconstituiriam numa condição facilitadora e de menor custo de resposta para a aquisição da leitura com compreensão, diminuindo a probabilidadedo "fracasso escolar"?

No trabalho de Souza e de Rose (1997), os autores investigaram a aquisição de um repertório rudimentar de leitura em crianças que não sabiam ler ou escrever, com idade entre 8 e 11 anos. Nos testes de equivalência, os Ps acertaram a maioria das palavras (as ensinadas e as de generalização). A explicação, dada pelos autores, é que as figuras nos testes de equivalência funcionaram como estímulos decomparação (escolha da figura correspondente à palavra impressa), facilitando o comportamento textual de leitura. Para Souza "poder-seia até mesmo considerar que neste caso o sujeito não estaria lendo, mas apenas nomeando uma das figuras (nenhum controle sobre 0 texto)" (p. 41). Após esses testes, foi feito mais um teste de leitura, em que uma palavra impressa consistia no único estímulo apresentado, sem o estímulo pictórico, com os Ps acertando apenas as palavras que lhe foram ensinadas.

A proposta de testes para verificar a ocorrência da generalização surgiu, em 1982, com Sidman e Tailby. 0 propósito dos autores foi verificar se o que foi ensinado aos Ps estava relacionado ou não com a emergência de novas classes de respostas (leitura generalizada), tendo por base os estudos iniciais sobre aquisição de leitura e escrita (Sidman, 1971), cujos Ps apresentavam algum tipo de deficiência.

Esta linha de pesquisa teve prosseguimento com alguns estudos realizados no Brasil (Aiello, 1995; Barros, 1996; Hanna \& cols., 1993; Hübner, 1997; Matos \& Hübner, 1997; Medeiros \& cols., 1997a; d'Oliveira, 1990; d'Oliveira \& Matos, 1993; de Rose, 1993; de Rose, Souza, Rossito \& de Rose, 1989; de Rose, Souza, Rossito \& de Rose, 1992). 
Para de Rose ${ }^{4}$, a partir dos anos 1980, houve um redirecionamento na pesquisa básica em Análise do Comportamento e, segundo ele, a equivalência deestímulos foi e continua sendo um dos temas mais freqüentemente propostos. D'Oliveira (1990), em sua tese de doutorado, relata o uso do paradigma de equivalência de Sidman (1986, 1994) no ensino da leitura. "Basicamente o quefez foi tentar estabelecer controle sobre o operante textual com unidades verbais menores que a palavra e, a partir daí, testar a ocorrência de leitura generalizada, empregando novas palavras, construídas com aquelasmesmas unidadesverbais" (citado em Matos, Hübner \& Peres, 1997, p. 471). A importância de unidades textuais mínimas na aquisição de leitura generalizada foi demonstrada, também, em vários estudos (Dixon, 1977; Matos \& Hübner, 1997; Melchiori \& cols., 1992; d'Oliveira \& Matos, 1993; de Rose \& cols.,1989, 1992; Souza \& Rose, 1992, 1997). Para d'Oliveira e Matos o controle pelas unidades mínimas apresentou-se melhor com a variação sistemática das sílabas, "ora como primeira sílaba, ora como segunda sílaba” (p. 105). Em um estudo posterior, Matos e Hubner (1997), novamente ensinaram palavras com as sílabas sistematicamentevariadas, "como ocorre no conjunto das palavras Bolo, Lobo, Boca e Cabo" (p. 50), com crianças não alfabetizadas. Com esse controle, os autores não só aumentaram o controle de estímulos como também diminuíram a variabilidade de desempenho.

Uma outra estratégia para se aumentar a probabilidade da generalização da leitura tem sido escolher palavras que já possuem significação para os Ps. Para Medeiros e colaboradores (1997b), as palavras a serem ensinadas deveriam ser procuradas no contexto social e familiar dos Ps. O s autores propõem a utilização de palavras dessa natureza porque, dentre os possíveis fatores que explicam o comportamento de leitura, está, provavelmente, “a utilização de palavras que já faziam parte do universo vocabular do sujeito possibilitando, desta forma, vincular o processo de aprendizagem com a sua realidade" (p.75). Essa estratégia foi desenvolvida e implementada por Freire (1978/1985) que, em sua principal obra, Pedagogia do oprimido, afirma: “ ... a investigação do tema gerador ... se realizada por meio de uma metodologia conscientizadora, além de possibilitar sua apreensão, insere ou começa a inserir os homens numa forma crítica de pensarem seu mundo" (p.113).

A emergência da generalização e mesmo a leitura das palavras de ensino podem ser dificultadas quando ocorrem

\footnotetext{
${ }^{4}$ Equivalência de estímulos, equivalência funcional e transferência de funções (Comunicação pessoal).
}

fatores extrínsecos ao procedimento, como variáveis familiares (Kleiman, 1993; Witter \& Lomônaco, 1987) e variáveis não acadêmicas utilizadas em sala de aula. A ridicularização (Leite, 1993; Tapia \& Fita, 1999), os preconceitos (Fini, 1998) e a punição excessiva (Skinner, 1974), freqüentemente utilizados pelo professor, são alguns deles. O uso freqüente dessas práticas produz sentimentos de incapacidade para aprender (Otta, 1986), de auto-estima diminuída, de desamparo ou de não saber o que fazer para mudar a situação (Seligman, 1975), gerando um estado de alienação (Nunes, 1990) e predisposição para a depressão severa edesistência (Skinner, 1974).

A metodologia derivada dos estudos de equivalência tem demonstrado que sua aplicação tem implicações educacionais importantes, como economia no ensino, pois o treino dealgumas classes derespostas produz a emergência de outras, além da possibilidade de ser aplicado a indivíduos com diferentes níveis de repertório (Aiello, 1995). De Rose (1993) aponta, também, sua importância para a educação. Segundo ele:

Estas relações de equivalência implicam na ocorrência de desempenhos emergentes, de tal modo que o indivíduo aprende mais do que foi explicitamente ensinado. Funções adquiridas diretamente por um estímulo e transferência de funções variam deacordo com o contexto, eestão subjacentes à compreensão do significado ... (além depoder ser ensinadas para) ... indivíduos deficientes mentais ou com dificuldade de aprendizagem. (p. 283)

Constitui-se, portanto, objetivo desse trabalho, verificar se testes de leitura, apresentados durante as etapas de um procedimento de matching (préteste, aprendizagem e pósteste), facilitariam a emergên cia denovas classes derespostas (leitura generalizada) e tendo como propósito responder à pergunta formulada, descreve-se, a seguir, os procedimentos experimentais destinados a essa finalidade.

\section{Método}

\section{Participantes}

Sete crianças foram os participantes do presente estudo. À época de sua realização, elas cursavam a 1a série do $1^{10}$ grau. Suas idades variavam entre 7 e 16 anos. As crianças foram escolhidas por indicação da direção da escola e das professoras, cujos critérios foram o índice de repetência e ausência do repertório de leitura e escrita. O projeto foi realizado nas dependências do Colégio Estadual Gaspar da Costa Moraes, em Itajaí, SC, escola que os Ps freqüentavam, nos turnos matutino evespertino. 
$\mathrm{O}$ atendimento foi individual, com as sessões (mais ou menos 20min) sendo realizadas três vezes por semana.

A Tabela 1 apresenta as características dos Ps, tais como sexo, idade, média das notas em Língua Portuguesa, número de repetências na primeira série e escolaridade dos pais. O bserva-se, nessa Tabela 1, que três Ps $(1,5$ e 6$)$ apresentam-se na faixa etária entre 7 e 8 anos; dois (P2 e P4) estão entre 8 e 9 anos; um (P3) está entre 9 e 10 anos e um (P7) entre 15 e 16 anos. Mais da metade dos Ps apresenta história de fracasso escolar: somente dois (P2 e P4) têm média superior a 5, sendo que o restante apresenta média inferior a 3,5. Três (P355, P5 e P6) já repetiram a 1a série, duas vezes e uma delas (P7), seis vezes. As outras

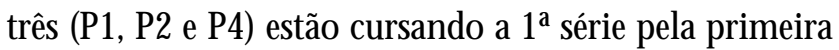
vez, mas, no $6^{\circ}$ mês após o início do ano letivo, ainda não sabiam ler e escrever. Em termos de escolaridade dos pais, dos sete Ps, somente a mãe de P4 tem o $3^{0}$ grau completo. Uma das mães (de P5) tem a $5^{\mathrm{a}}$ série completa e uma (de P2) é analfabeta. As demais (de P1, P3, P4 e P7) têm a 1a série incompleta. Em relação aos pais, um (de P2) tem a 2⿳a série completa, um (de P5) é analfabeto, um não respondeu (de P4) e os demais (de P1, P3, P6 e P7) têm, também, somente, a 1a série incompleta.

\section{Material}

Os estímulosvisuais, constituídos de palavras e figuras, foram apresentados aos Ps, impressos em folhas de papel, tamanho ofício e encaixadas em pastas com folhas plásticas transparentes.

Cubos de madeira, com letras medindo $2 \mathrm{~cm}$ de largura por $2 \mathrm{~cm}$ dealtura eimpressas em suas superfícies, foram utilizados na etapa de montagem das palavras. Foram usados dois tipos de folhas de registro, sendo uma para registrar as respostas ao conjunto de palavras AAA e outra para registrar as respostas ao conjunto de palavras ABA. Em AAA, as palavras de generalização foram as mesmas, tanto nas etapas dos pré e pós-testes, como na etapa de aprendizagem. Já, em ABA, as palavras de generalização das etapas dos pré e pós-testes foram as mesmas, porém diferentes das palavras apresentadas na etapa de aprendizagem.

Tabela 1

Característicasdos Participantes: Sexo, Idade, Média Final em Língua Portuguesa, RepetênciaseEscolaridadedos Pais

\begin{tabular}{|c|c|c|c|c|c|c|c|}
\hline & & AAA & & & & $\mathrm{ABA}$ & \\
\hline Participante & P1 & $\mathrm{P} 2$ & $\mathrm{P} 6$ & P7 & P3 & $\mathrm{P} 4$ & $\mathrm{P} 5$ \\
\hline Sexo & $\mathrm{F}$ & $\mathrm{M}$ & $\mathrm{F}$ & $\mathrm{M}$ & $\mathrm{F}$ & M & M \\
\hline Idade & 7,10 & 8,11 & 7,8 & 15,10 & 9,8 & 8,11 & 7,4 \\
\hline Língua Portuguesa & 3,5 & 5,8 & 2,8 & 3,0 & 3,0 & 6,9 & 3,2 \\
\hline Repetências & - & - & 2 & 6 & 2 & - & 2 \\
\hline Escolaridade do pai & $\begin{array}{c}1^{\mathrm{a}} \text { série } \\
\text { incompl. }\end{array}$ & $2^{a}$ série & $1^{0}$ série & $\begin{array}{l}1^{\mathrm{a}} \text { série } \\
\text { incompl. }\end{array}$ & $\begin{array}{l}1^{\mathrm{a}} \text { série } \\
\text { incompl. }\end{array}$ & - & Analf. \\
\hline Escolaridade da mãe & $\begin{array}{c}1^{\mathrm{a}} \text { série } \\
\text { incompl. }\end{array}$ & Analf. & $1^{\circ}$ série & $\begin{array}{c}1^{\mathrm{a}} \text { série } \\
\text { incompl. }\end{array}$ & $\begin{array}{c}1^{\mathrm{a}} \text { série } \\
\text { incompl. }\end{array}$ & $3^{\circ}$ grau & 5 série \\
\hline
\end{tabular}

Tabela 2

Representação Esquemática da Seqüência dePassosdo Programa deEnsino: Cada Tipo dePasso (Linha deBase, Aprendizagem, Equivalência ou Teste) está Numerado deacordo com sua Ordem deInserção no Programa

\begin{tabular}{clcl}
\hline Passos & \multicolumn{1}{c}{ Fases } & Passos & Fases \\
\hline 1 & Teste de leitura & 11 & Exclusão 5 \\
2 & Linha de base I & 12 & Exclusão 6 \\
3 & L.B.II (Equivalência) & 13 & Equivalência 3 \\
4 & Exclusão 1 & 14 & Exclusão 7 \\
5 & Exclusão 2 & 15 & Exclusão 8 \\
6 & Equivalência 1 & 16 & Equivalência 4 \\
7 & Exclusão 3 & 17 & Exclusão 9 \\
8 & Exclusão 4 & 18 & Exclusão10 \\
9 & Equivalência 2 & 19 & Equivalência 5 \\
10 & Teste 1 & 20 & Teste 2 \\
\hline
\end{tabular}

${ }^{5}$ Á época, P3 apresentava bronquite e podia-se notar que respirava com dificuldade. 


\section{Procedimento}

Antes do procedimento propriamente dito ter sido iniciado, foi realizada, com cada um dos Ps, uma conversa informal, com duração de mais ou menos 15 minutos, cujo conteúdo foi gravado. $\mathrm{O}$ objetivo foi coletar as palavras do universo vocabular da criança queforam utilizadas no teste inicial deleitura.

O procedimento, composto de 20 passos (Tabela 2) consistiu na presença, em cada tentativa de pareamento, de uma palavra como etímulo modelo e de duas palavras como estímulos de cmparação, sendo uma delas conhecida pelo participante e a outra desconhecida.

A Tabela 2 apresenta um esquema do fluxo do programa de ensino. $O$ programa foi dividido em uma seqüência de passos. Os passos 2 e 3 foram destinados à aquisição de uma linha de base inicial, que se expandiu com o emprego do procedimento de matching. O programa prosseguiu alternando passos de ensino, onde as palavras novas foram ensinadas pela exclusão das palavrasjá ensinadas, com passos de testes de equivalência e de testes de leitura (numerados seqüencialmente). Testes de equivalência foram realizados depois de cada dois passos de ensino para verificar a formação deequivalência entreos estímulos palavraimpressa, palavra ditada e figura. Testes de leitura foram também realizados para verificar a leitura de todas as palavras de ensino ede generalização introduzidasatéaquelemomento. 0 Teste 1 foi realizado na metade e o Teste 2 foi realizado ao final do programa.

As tentativas corretas foram reforçadas nos passos onde estivessem ocorrendo o procedimento de ensino de novas relações (palavras ditadas - palavras impressas), através de expressões tipo "muito bem", "correto", "ótimo" (e outras expressões que exprimiam incentivo). Q uando 0 experimentador (E) apresentava o modelo correspondente ao estímulo novo, o estímulo de comparação já conhecido funcionava como pista para que o participanteo rejeitasse e selecionasse corretamente o estímulo novo. Assim, nesse programa, o procedimento permitiu a aprendizagem sem erro do pareamento de palavras ditadas com palavras impressas.

Após duas tentativas consecutivas de ensino da primeira palavra, deu-se início à montagem dessa palavra. Nessa condição, o E apresentou a palavra modelo e distribuiu, aleatoriamente, as letras dessa palavra sobre a mesa, dizendo ao participantepara montá-la: "Agoravocêvai escrever com estas letrinhas, a palavra ... (e dizia o nome da palavramodelo)". Após o participante ter montado a palavra corretamente, era reforçado e o E solicitava que a lesse, dizendo: "Que palavra você escreveu?" O mesmo procedimento ocorreu com as outras duas palavras. Se 0 participante não realizasse corretamente a montagem, o E pedia para tentar outra vez: "Vamos tentar mais uma vez?" Caso o participantenão conseguisse montar a palavra na $2^{\text {a }}$ tentativa, o E sugeria: "Presteatenção na palavra (o E indicava a palavra impressa). Agora tente montar a palavra".

Os passos envolveram, cada um, o ensino de três palavras (com nove tentativas de escolha para cada uma). As tentativas iniciais de um passo constituíram-se num préteste que avaliou a leitura das palavras de ensino que foram introduzidas no passo, das palavras ensinadas na sessão imediatamente anterior (retenção) e também de três palavras de generalização.

Em cada passo foram também introduzidas palavras de generalização, na forma de testes intertentativas, em número de três ou seis, dependendo do conjunto utilizado (se AAA ou ABA), sendo formadas a partir da combinação das sílabas das palavras de linha de base anterior. Essas palavras foram inseridas entre as tentativas das etapas da exclusão (Préteste, Aprendizagem e Pós-teste) - frente às quais nenhuma contingência reforçadora foi fornecida por ocasião das respostas do participanteà solicitação deleitura por parte do E. Nos testes intertentativas, inseridos entre as tentativas das etapas da exclusão (Préteste, Aprendizagem e Pós-Teste), como pode ser visto na Tabela 3, os conjuntos

Tabela 3

Diagrama da Seqüência eFreqüêndia deA presentação dos Testes deLeitura (Palavras deGeneralização) nasDiferentes Etapas da Exclusão

\begin{tabular}{lcccc}
\hline & Conjunto AAA & Tentativas & Conjunto ABA & Tentativas \\
\hline Pré-teste & $\mathrm{A}$ & 3 & $\mathrm{~A}$ & 3 \\
Aprendizagem & $\mathrm{A}$ & 6 & $\mathrm{~B}$ & 6 \\
Pós-teste & $\mathrm{A}$ & 3 & $\mathrm{~A}$ & 3 \\
\hline
\end{tabular}

Tabela 4

Número de Sessões Realizadas œm cada um dosParticipantes

\begin{tabular}{llllllll}
\hline Participante & S1 & S2 & S3 & S4 & S5 & S6 & S7 \\
No de sessões & 31 & 22 & 35 & 25 & 21 & 42 & 36 \\
\hline
\end{tabular}


Tabela 5

Relação das Palavras deEnsino edas Palavras deGeneralização. 0 Conjunto AAA foi Formado pelasPalavrasdeGeneralização A eo Conjunto ABA foi Formado pelasPalavras deGeneralização A eB, œm B sendo A presentado apenasna Etapa deAprendizagem

\begin{tabular}{ccc} 
& \multicolumn{2}{c}{ Palavras de } \\
\cline { 2 - 3 } Linha de base & Ensino & Generalização \\
Excl.1 & Cala, D oce, Ovo & Vovô, Lado, Cela \\
Excl.2 & Pai, Escola, Lápis & Saia, Cala, Dica \\
Excl.3 & Aula, Ler, Menina & Cola, Lapa, Papa \\
Excl.4 & Salada, Suco, Boca & Miau, Lama, Ana \\
Excl.5 & Barco, Cama, Boneca & Caneca, Boné, Mano \\
Excl.6 & Roupa, Caderno, Livro & Cano, Capa, Parou \\
Excl.7 & Carne, Morango, Leite & Gota, Tela, Gol \\
Excl. 8 & Pente, Gaveta, Mesa & Tevê, Gaga, Pensa \\
Excl. 9 & Cadeira, Escova, Balde & Cara, Escada, Vaca \\
Excl.10 & Pasta, Tesoura, Relógio & \\
\hline
\end{tabular}

de palavras AAA e ABA foram utilizados. Assim, foram apresentadas, tanto para AAA quanto para ABA, três tentativas no préteste, três tentativas no pós-teste e seis tentativasna etapa deaprendizagem, sendo mostrada apenas uma palavra em cada tentativa. Como essas palavras são freqüientemente apresentadas apenas nas etapas dos pré e pós-testes, pretendeu-se, com a inserção das palavras de generalização entre as tentativas reforçadas, verificar se a leitura emergentedestas palavras surgiria com maior rapidez eeficiência.

A leitura correta de todas as palavras ensinadasna sessão anterior duranteo prétesteconstituiu-senum requisito para a realização do ensino de novas palavras: se 0 critério não fosseatingido, o passo anterior era repetido. Assim, o tempo de participação no programa foi variável para cada participante, podendo-se observar, na Tabela 4, o número de sessões realizadas com cada um deles.

A Tabela 5 apresenta a relação das palavras de ensino, bem como a relação das palavras degeneralização, formadas a partir das sílabas das palavras ensinadas na aprendizagem anterior.

\section{Análise dos Dados}

Foram consideradas como leitura correta as porcentagens das palavras de generalização compreendidas entreosvalores de 80 e 100\% do gráfico e essa faixa foi denominada de área critério do gráfic. Para afirmar sehouveou não diferença entre as etapas, os valores percentuais situados nessa área foram contados e o resultado foi utilizado para comparar o desempenho entre as etapas de Pré/ Pós-testes e Aprendizagem. Foram também utilizados para esta comparação apenas os dados da primeira e última sessão de cada etapa.

\section{Resultados}

A Figura 2 foi construída com os valores percentuais de leitura correta das palavras de generalização (Conjunto AAA) da primeira e última sessão de cada fase das etapas de Prél Pós-testes e Aprendizagem dos Ps 1 e 2. Pode-se ver que há, para P1, 26 sessões cujos valores localizam-se na área critério, enquanto para P2 há apenas 10 sessões com valores localizados em área semelhante. Quando comparadas entre si, verifica-se, claramente, uma grande variabilidade entre as sessões, para ambos os Ps. Pode-se verificar, ainda, que as baixas porcentagens acontecem, na maioria das vezes, na primeira sessão de cada etapa, sendo que na última sessão os resultados são sempre mais elevados. $\mathrm{O}$ aumento no percentual deacertos nas últimas sessões demonstra que, no decorrer do processo, o comportamento de leitura das palavras de generalização ocorreu para ambos os Ps, em especial para P1, com maior percentual de leitura correta.

A Figura 3 apresenta os dados de P6 e P7 (Conjunto AAA). Observa-se reduzida porcentagem de acertos para ambos os Ps, com uma elevada predominância de taxas com valores zero. 0 maior valor percentual alcançado por P6 foi de 66,6\%, na 1ª sessão da Excl. 9 (Préteste); os demais percentuais mantém-se em 33,3\%. Já, os percentuais de $\mathrm{P7}$, além de serem mais elevados que os de P6, estão, em duas sessões (Aprendizagem e Pós-teste), localizadas dentro da área critério. Valores percentuais de 66,6\% são alcançados, por P7, por três vezes e de 33,3\%, por seis vezes, demonstrando que os dois Ps (P6 e P7) apresentam um padrão de generalização inferior ao apresentado pelos Ps 1 e 2 . 


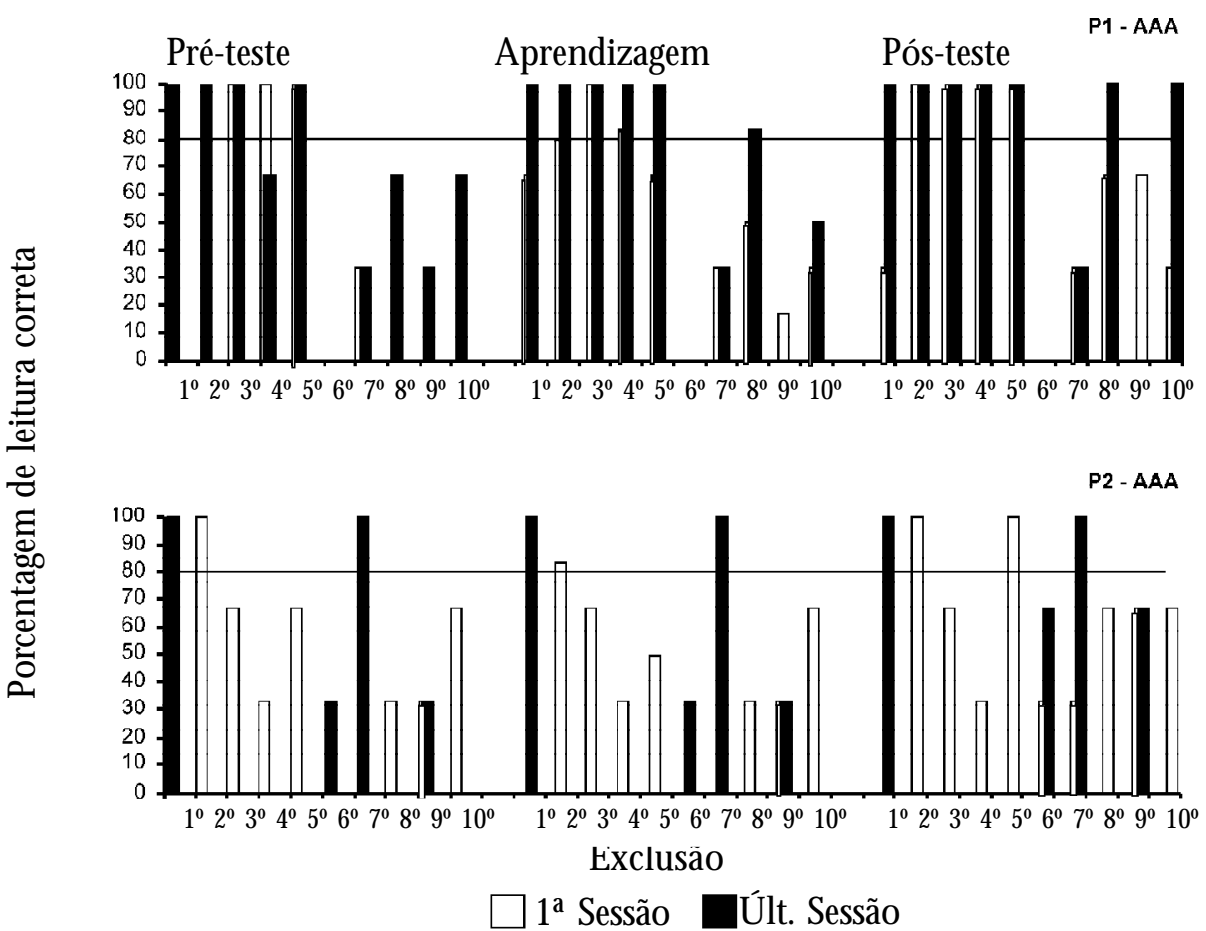

Figura 2. Porcentagem deleitura correta de $\mathrm{P} 1$ (parte superior) e $\mathrm{P} 2$ (parteinferior) relativa às palavras de generalização do conjunto AAA da $1^{a} \mathrm{e}$ última sessão de cada exclusão. 0 número da exclusão com asterisco indica que o critério, na fase de ensino, foi alcançado em uma única sessão.

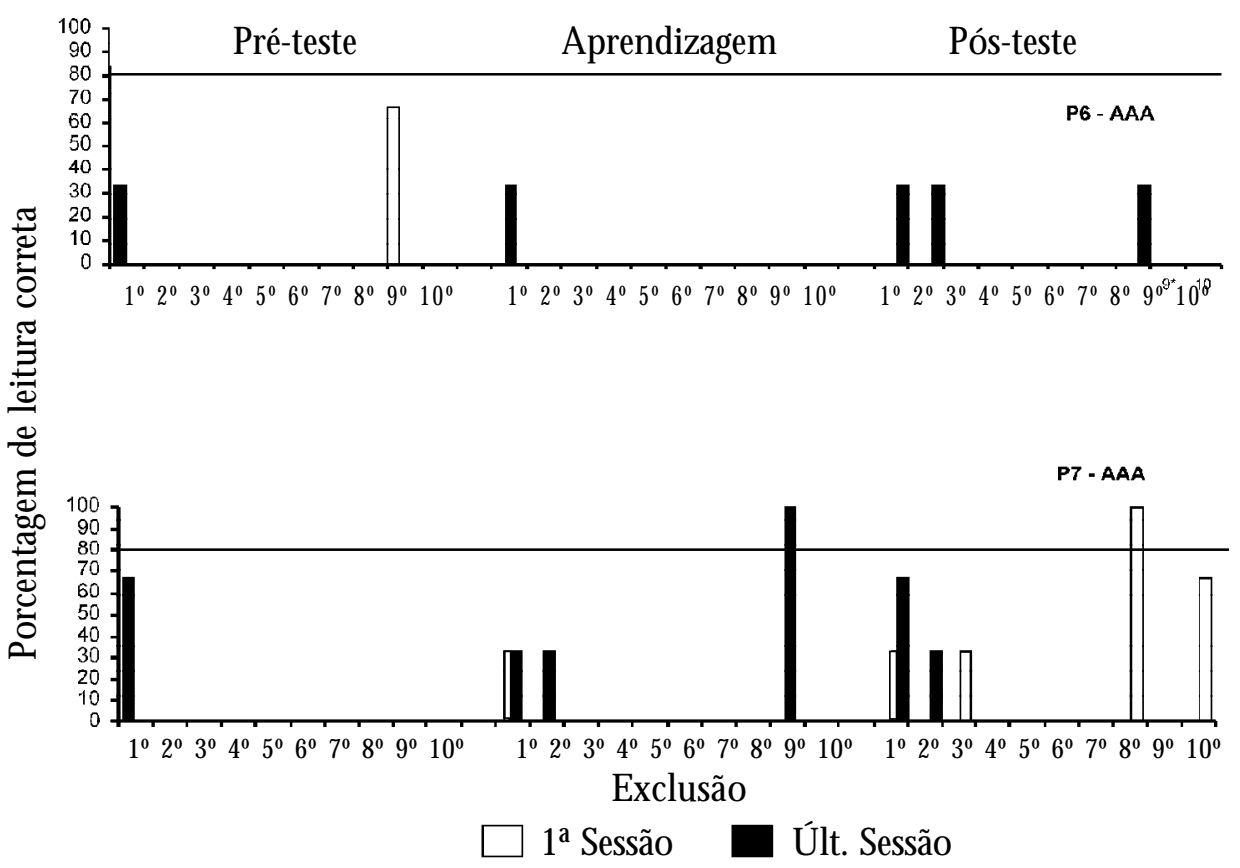

Figura 3. Porcentagem deleitura correta de P6 (parte superior) eP7 (parteinferior) relativa às palavras de generalização do conjunto AAA da $1^{\mathrm{a}} \mathrm{e}$ última sessão de cada exclusão. 0 número da exclusão com asterisco indica que o critério, na fase de ensino, foi alcançado em uma única sessão. 
A Figura 4 apresenta os resultados dos Ps 3,4 e 5 (Conjunto ABA). Há, para P3, 12 sessões com valores localizadosna área critério, enquanto que, para P4, são 17 e, para P5, são 16 sessões com valores localizados em área semelhante, demonstrando, portanto, queesses participantes apresentam o comportamento de generalizar. Observa-se, quando comparados os valores percentuais das etapas de Pré/ Pós-testes dos Ps 4 e 5, um aumento do percentual de respostas corretas no Pós-teste, havendo, para P4, um aumento dequatro para oito sessõese, para P5, um aumento de quatro para seis sessões dentro da área critério. Para P3, entretanto, há uma diminuição de quatro para três sessões.

Comparadas entre si, verifica-se que há uma grande variabilidade entre as sessões, para os três Ps. Comparandose os valores percentuais de $\mathrm{P} 3, \mathrm{P} 4$ e P5, pode-se notar que os Ps 4 e 5 apresentam desempenho superior em relação ao desempenho de P3, principalmente, na Etapa do PósTeste, onde, P4 apresenta oito e, P5 apresenta seis sessões com $100 \%$ de acerto de leitura correta, enquanto que P3 o faz, somente, em três sessões. Os dados de P4 eP5 indicam, portanto, um padrão de generalização superior ao padrão apresentado por P3.

Deerição dasporcentagensobtidasnostetesesdeequivalênaia

Todos os Ps (AAA e ABA) estabeleceram as relações entre as palavras faladas, palavras impressas e figuras, pois os índices percentuais de acertos são elevados e estão compreendidos entre os valores de 80 e $100 \%$, nos seis testes de Equivalência. A Equivalência1 éo único testeonde se verificam percentuais inferiores a 100\%; é o caso dos Ps 1, 2 e 6 (Conjunto AAA) e de P4 (Conjunto ABA).

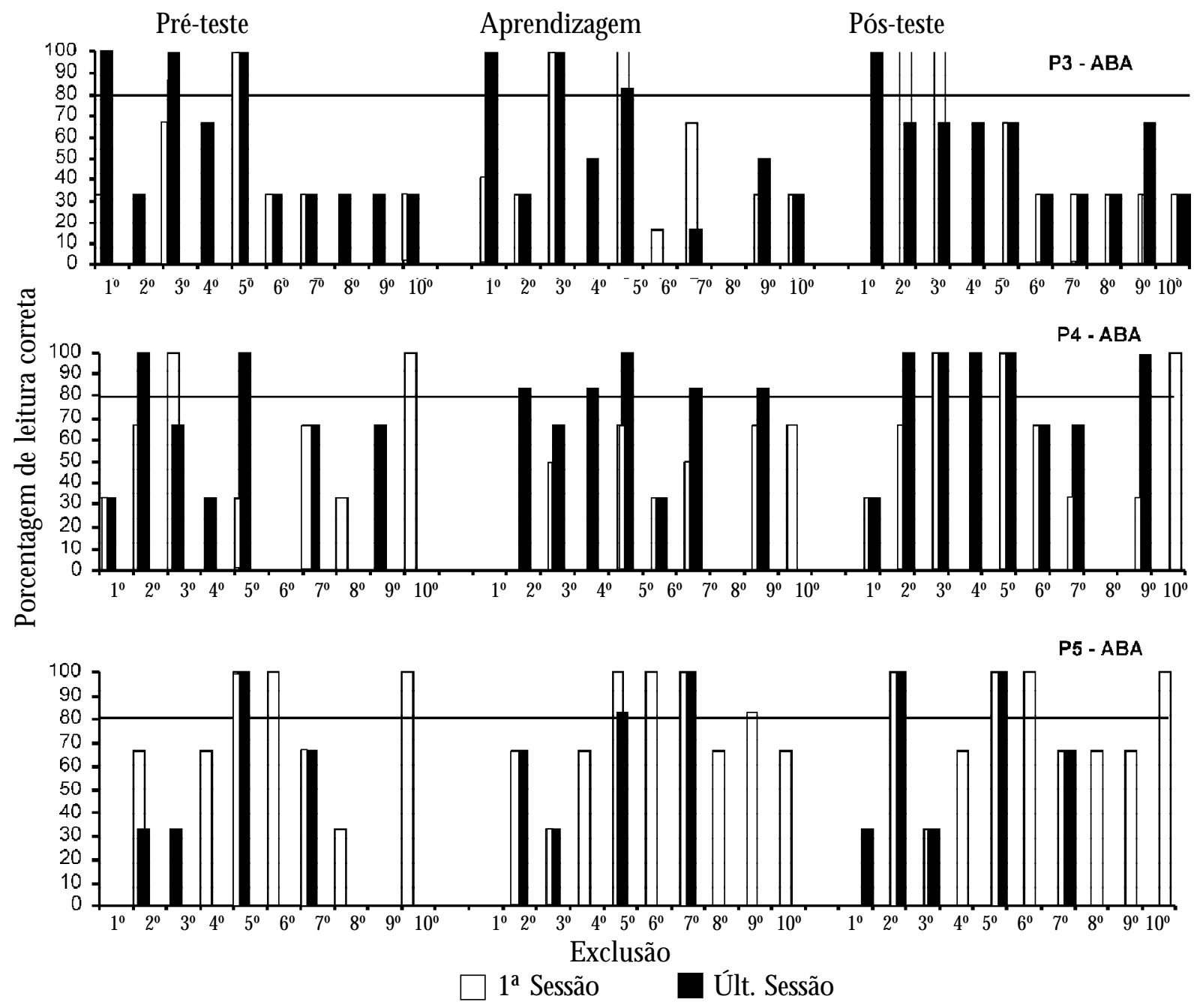

Figura 4. Porcentagem de leitura correta de P3 (parte superior), P4 (parte intermediária) e P5 (parte inferior) relativa às palavras de generalização do conjunto $\mathrm{ABA}$ da $1^{\mathrm{a}} \mathrm{e}$ última sessão de cada exclusão. $\mathrm{O}$ número da exclusão com asterisco indica que o critério, na fase de ensino, foi alcançado em uma única sessão. 
Descrịão das porentagens obtidasnostestes extensivos deleitura

A Figura 5 apresenta os dados relativos aos testes de leitura das palavras de ensino e degeneralização (realizado na metade eno final do programa) dos Ps dos Conjuntos AAA, na parte superior e ABA, na parte intermediária da Figura; na parte inferior, encontram-se as médias de acertos dos P5 de ambos os conjuntos.

A porcentagem de P1 e P2 apresenta-se acima de $75 \%$, tanto em relação às palavras de ensino, como em relação às palavras de generalização, demonstrando que ficaram sob controle das unidades mínimas, isto é, identificavam as sílabas das palavras de ensino quando estas apareciam na composição denovas palavras e, assim, mostrando leitura com compreensão. Já, para P6, no $1{ }^{0}$ teste, o percentual é próximo de $90 \%$ de leitura correta, tanto das palavras de ensino, como de generalização tendo, no $2^{\circ}$ teste, respondido com uma taxa de $30 \%$ em relação às palavras de ensino e 40\% em relação às palavras de generalização. P7 demonstrou estar sob controle reduzido das unidades mínimas, pois seu desempenho se mantem sempre abaixo dos 33,3\% no decorrer dos dois testes.

No conjunto ABA (parte intermediária da Figura 5), onde as palavras de generalização apresentadas na etapa de aprendizagem foram diferentes das apresentadas nas etapas dos pré e pós-testes, a porcentagem de P5 é de 90\% de leitura correta, em todos os testes (das palavras de ensino à esquerda e das palavras de generalização à direita da figura), demonstrando ter adquirido o comportamento de leitura com compreensão. P4 demonstrou, também, ter ficado sob controle das unidades mínimas, com percentuais
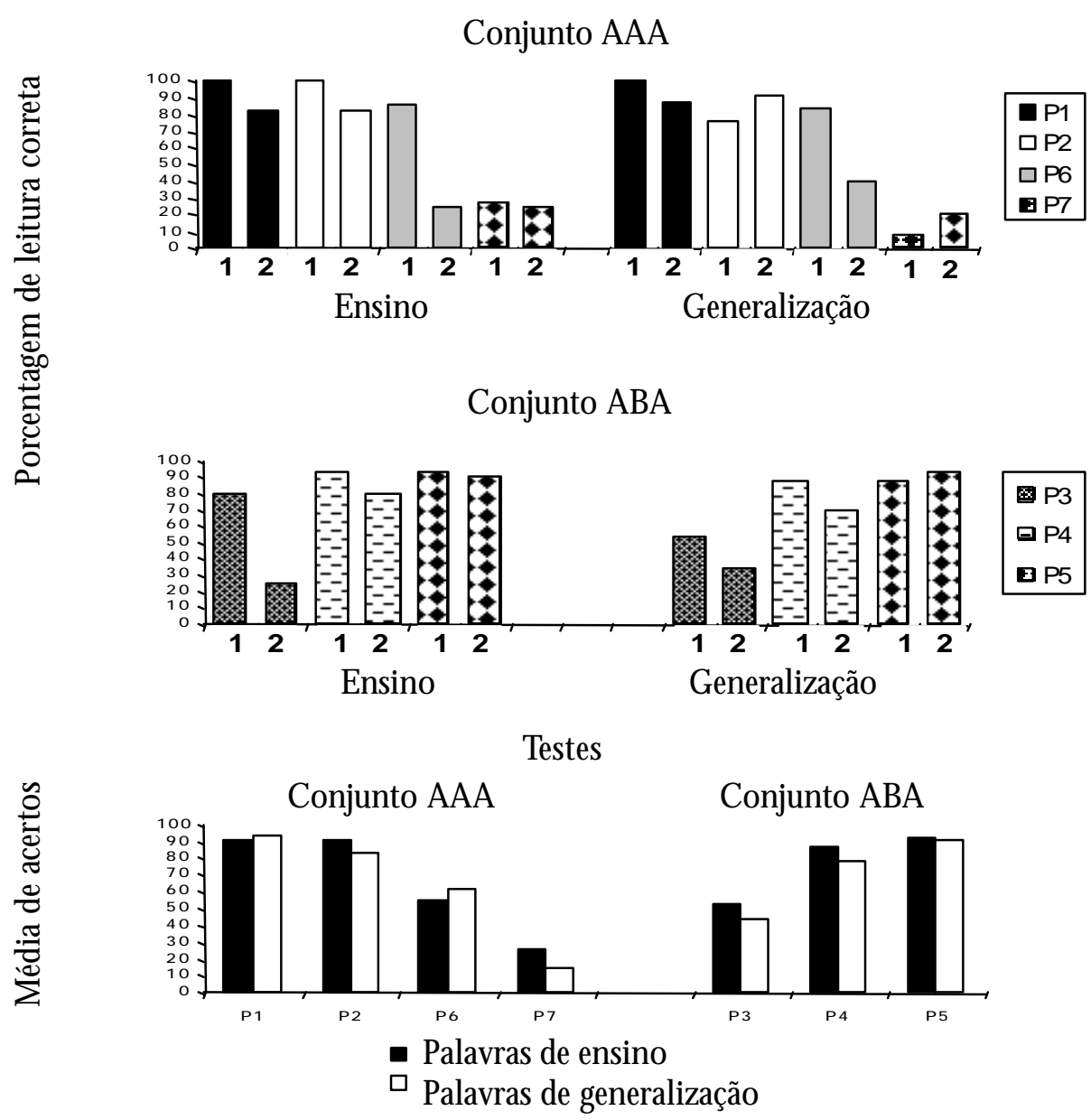

Figura 5. Porcentagem de leitura correta nos testes finais de leitura das palavras do conjunto AAA: no alto, à esquerda, testes 1 e 2 das palavras de ensino e, à direita, testes 1 e 2 das palavras de generalização; no meio, testes semelhantes porém do conjunto ABA; embaixo, média de acertos de todos os Ps de ambos os conjuntos 
próximos de 90, nos teste 1 das palavras de ensino e de generalização. No teste2 daspalavras deensino, o percentual diminui para 80\% e, no degeneralização, diminui para $75 \%$. Já, para P3, no $1^{\circ}$ teste, o percentual de leitura das palavras de ensino é de 80 por cento e das palavras de generalização é de $50 \%$, sendo que, no 20 teste, a porcentagem decai para abaixo de 33,3\% nas palavras de ensino e abaixo dos $40 \%$ nas palavras de generalização, demonstrando, assim, ter ficado sob controle reduzido das unidades mínimas. Comparando-se os dois conjuntos, observa-se que os percentuais de acertos em ABA são mais elevados que os do conjunto AAA.

As médias de acertos, para P1 e P2 de AAA e, para P4 e P5 de ABA, situam-se entre 86 e 92 por cento para as palavras de ensino e, com amplitude maior de variação, ou seja, entre 78 e 94 por cento para as palavras degeneralização. As médias mais baixas, tanto das palavras de ensino como de generalização, são dos Ps 6 e 7 de AAA e de P3 de ABA. As médias das palavras de ensino variam entre 25 (P7) e 56 por cento (P6) e as de generalização variam entre 14 (P7) e 62 por cento (P6). Para esses três Ps (6, 7 e 3), a amplitude de variação das médias das palavras de generalização é, também, maior do que a amplitude das médias das palavras deensino.

\section{Discussão}

Os resultados obtidos nesse estudo demonstram que cinco, dos sete Ps, passaram a ler palavras novas sem que, para isso, tivessem sido ensinados, resultando, portanto, na respostaà pergunta formulada no início dessetrabalho: quais foram os efeitos de testes de leitura, apresentados entre tentativas reforçadas da etapa de aquisição ou aprendizagem, sobre a leitura de palavras novas ou leitura generalizada? Inicialmente, podesedizer quenão há efeito diferencial visível entre os dois conjuntos de palavras utilizados, pois tanto AAA quanto ABA facilitaram a emergência deleitura, com pequena predominância de leitura correta para os participantes do conjunto ABA (dos três participantes de ABA, dois apresentam leitura generalizada e um, P3, apresenta leitura com acertos em torno de $40 \%$, enquanto que dos quatro participantes de AAA, dois mostram emergência de leitura de novas palavras; um, P6, apresenta leitura correta em torno de 60\% eum, P7, apresenta leitura generalizada com porcentagem em torno de $20 \%$ ).

Que fatores poderiam explicar as porcentagens baixas em relação às palavras de generalização? Certamente, um deleséo grau de dificuldade dealgumas palavras, cuja análise indicará os tipos de composição silábica, bem como os erros decorrentes.
Todos os Ps, ao longo do programa, independente de pertencerem ao conjunto AAA ou ABA, estabeleceram as relações entre a palavra falada, a palavra escrita e as figuras correspondentes, resultando num percentual elevado de acertos nos testes de equivalência.

Os resultados, nos testes finais das palavras de ensino, são, também, elevados para a maioria dos Ps (com exceção de P7), com porcentagem de leitura correta mais elevada no Teste 1 do que no Teste 2. Possivelmente, o percentual elevado de acertos nesse teste deva-se ao fato do mesmo ter ocorrido no meio do programa e, também, por ser menor o número de palavras ensinadas do que no Teste 2 , que ocorreu ao final do programa. Nos estudos relatados sobre equivalência de estímulos, o comportamento textual é ensinado através da exclusão da palavra conhecida, onde palavras inteiras, com seus significados, são apresentadas aos Ps. Na medida em que novas palavras são apresentadas, as sílabas que as compõem passam a controlar a leitura, tanto a textual quanto a emergente. Ou seja, a recombinação silábica constitui-se na principal condição dessa forma de ensinar, além da emergência da nomeação generalizada de palavras (Souza \& de Rose, 1997).

Que outros fatores explicariam o alto percentual de acertos das palavras de ensino? 0 uso de contingências reforçadoras, de natureza social, tais como as expressões verbais, ótimo, estou gostando, vgja como voĉpode, certo, correto, exclente, pode ser um deles. Mesmo assim, o controle de estímulos, resultante dessas contingências, começou a enfraquecer-se no decorrer do estudo, resultando em falta de atenção durante as sessões, confirmando, desse modo, os resultados de A. W. Staats, C. K. Staats, Schutz eWolfe (1962). As crianças desse estudo não se mantiveram trabalhando num programa deleitura quando as respostas eram seguidas apenas por reforço social. Procurou-se, no presente estudo, criar novas condições estimuladoras no sentido de tornar os Ps mais interessados nas atividades desenvolvidas. Foi então que, a partir da Exclusão 3, ao final de cada sessão, quando os Ps atingiam o critério de mudança de uma etapa de aprendizagem para outra, foi dado, a cada participante, um objeto escolar (lápis, borracha, régua, etc.), sempre acompanhado das afirmativas pelo su eforç, vejo quevocêestá seefforçando, etc. Observou-se queesta contingênđa auxiliar foi efetiva paraa adesão ao procedimento, pois eles passaram a vir mais rápido para as sessões e concentraram-se mais na tarefa.

Em relação às palavras de generalização, os dados dos testes finais demonstram que, dos sete Ps, quatro (Ps 1 e 2 AAA; Ps 4 e 5 - ABA) obtêm percentuais de acertos acima dos $80 \%$ e três (Ps 6 e 7 - AAA; P3 - ABA) abaixo de $40 \%$. Comparado com o desempenho de leitura das palavras de ensino, a emergência de leitura generalizada foi apenas 
parcial. Uma provável explicação para a porcentagem baixa deleitura correta (abaixo de 40\%) da maioria dessas palavras, para os Ps 6 e 7 (conjunto AAA) e P3 (conjunto $\mathrm{ABA}$ ), pode ser devido à história de repetência e de notas baixas em Língua Portuguesa. A exceção é P5, também com essa história, porém sua nota em Língua Portuguesa é um pouco superior $(3,2)$ às dos demais participantes $(2,8$; 3,0 e 3,0) e a escolaridade de sua mãe é também superior ( 5 a série completa), além de possuir a menor idade entre os quatros. Esse conjunto de fatores pode ter influenciado 0 desempenho dos Ps 6, 7 e 3 ao encadear as sílabas componentes das palavras. Possivelmente, a ausência de repetição sistemática dassílabas duranteo ensino daspalavras tenha dificultado a leitura correta da maioria delas. Segundo Matos e Hübner (1997), “ ... as unidades silábicas não repetidas geram controle textual parcial e idiossincrático" (p. 50). Exemplificando, vejam as palavras de ensino Bala e Doc da Exclusão 1. Observa-se que, como afirmam os autores, as unidades silábicas das palavras ensinadas não se repetem, dificultando, assim, o controle textual. A segunda constatação foi que "unidades silábicas que ocupam as mesmas posições em diferentes palavras tornam-se redundantes e não exercem controle sobre 0 comportamento textual" (p. 50). Segundo estes autores, para a ocorrência da generalização, a repetição silábica deveria ocorrer em diferentes posições nas palavras ensinadas. Em outras palavras, o conjunto de palavras ensinadas deveria conter sílabas repetidas em lugares diferentes, de forma que as unidades silábicas, ensinadas, seriam reforçadas, tanto no início, meio e fim das palavras; p.ex., se as palavras BOLO e LOBO tivessem sido ensinadas, a ślaba BO apareceria no início da palavra BOLO e se repetiria ao final da palavra LOBO, caracterizando, assim, a inversão silábica. Esse tipo de composição, provavelmente, facilitaria a leitura das palavras de generalização, como sugerem Matos e Hübner.

O mesmo pode ser afirmado em relação às palavras de ensino Bala eDoce(conjunto AAA, Excl. 1) quederam origem à formação da palavra de generalização Lado; observem queas unidades silábicas la edo não se repetem na formação daspalavras de ensino, gerando, assim, controleparcial sobre a palavra degeneralização, com acerto acima de $33 \%$ apenas para dois Ps (1 e 2). Segundo Matos e Hubner (1997), “ ... porque as unidades silábicas não se repetem nas diferentes palavras, qualquer uma delas (i. e., das sílabas) podecontrolar os operantes discriminativos textuais ..." (p. 50). Esta falta de sistematização na formação das novas palavras repetiuse com outras palavras, como pode ser visto na Tabela 5, excluindo, assim, a possibilidade de uma mesma sílaba ser reforçada em diferentes posições, como argumentam Matos e Hubner (1997). Não há dúvida quanto à explicação promissora das autoras, contudo, no presente estudo, um controle dessa natureza não poderia ter sido organizado, pois as palavras utilizadas para o ensino foram retiradas do universo vocabular das crianças.

A presença do acento circunflexo pode ter se constituído em outra dificuldadenaleitura das palavras de generalização da Etapa da Aprendizagem da Excl. 1 e 9. Na Excl. 1, a ordem silábica foi respeitada, mas houve 0 acréscimo do acento. Primeiramente, foram ensinadas as palavras Ovo e Docemontadas aspalavras de generalização Vovô (Conjunto AAA) eVocê(Conjunto ABA). Na Excl. 9, o uso do acento se repete, acrescido da inversão silábica, por exemplo, com a palavra de generalização Tevê(conjunto AAA), ondeforam ensinadas, primeiramente, as palavras Pentee Gaveta.

Erros de fonética, também, foram constatados, por exemplo, com a palavra Parou (Excl. 7), derivada de Roupa (Linha de Base), que foi lida incorretamente, talvez em função do som diferenciado de ambas as palavras (parou com som de um $r$ e roupa com som de dois rr) e, nesse caso, lida como Parrou; ainda, em relação a essas palavras (Roupa e Parou), ocorreu também a inversão de Rou para o final da palavra, o que pode ter dificultado a leitura, pois, na Linha de Base, foi reforçada uma palavra com Rou na posição inicial. A palavra Cara (Excl. 10) apresentou, também, a mesma dificuldade, sendo lida como Carra. A palavra Ana (Excl. 4) apresentou dificuldade pela presença do som nasal ${ }^{6}$; a sílaba $\mathrm{Ma}$, da palavra Mano (Excl. 6), apresenta, também, som nasal, diferente do som oral da sílaba Ma da palavra Cama (Linha de Base). Assim, o participante foi reforçado, em primeiro lugar, a ler o Ma (oral) deCama (Linha deBase), sendo apresentado, posteriormente, a palavra Mano (nasal). A dificuldade deleitura da palavra Mano poderia, também, ser explicada pela exigência da pronúncia do som nasal, pois, na maioria das vezes, essas crianças aprendem a ler soletrando as letras ou mesmo unindo-as por grupos. Nesse caso, não conseguem ler com a pronúncia correta ou mesmo desistem por não compreenderem o significado da palavra, pois a tendência delas é ler a letra A (oral Máno) quando deveria ser lida com um som anasalado (Mâno). A palavra Cano (Excl. 7) pode, também, ter produzido resultado semelhante. Na linha de Base foi apresentada a palavra Caderno (som oral), enquanto que na Generalização foi apresentada a palavra Cano (som nasal). O mesmo pode ser afirmado a respeito da palavra Pensa (Excl. 9), pela presença da letra n, com um som nasal intercalado entreas sílabas.

\footnotetext{
${ }^{6}$ Segundo a Nomenclatura Gramatical Brasileira, as vogais devem ser classificadas de acordo com os seguintes critérios: ... Orais - a corrente de ar ressoa apenas na cavidade bucal. Nasais - a corrente de ar, encontrando 0 véu palatino abaixado, ressoa também na cavidade nasal. (Terra E. 91, p. 10).
} 
A semelhança entre palavras de generalização, apresentadas em exclusões próximas, pode ter sido um fator que favoreceu a leitura incorreta. Os Ps 6 e 7 (AAA) e P5 (ABA) leram Cola (Excl. 3) como Cala. Possivelmente, esta troca de letras (a por o) se deu pelo fato de, na Exclusão precedente (Excl. 2), a palavra de generalização apresentada ter sido Cala.

Os Ps 3 e 5, na Excl. 2, leram incorretamente a palavra degeneralização Saia, com o ditongo ia, no final da palavra; a tendência foi ler Saa, omitindo a vogal i intermediária. Isto, possivelmente, se deu pelo fato do $\mathrm{P}$ dominar somente a vogal a. O bservou-se, ainda, a leitura da palavra Saia como Sabia, por P4, havendo, nesse caso, 0 acréscimo da consoante b. $O$ desconhecimento das vogais (no caso, a vogal u) pode, também, ter provocado leitura incorreta da palavra Miau (Excl. 4), por P2, sendo lida como Mia ou ainda Mi. A palavra Escada (Excl. 10) foi lida, por P1, na terceira aplicação da Excl. 10, como Esauda, havendo a troca da vogal a por u.

A falta de domínio das consoantes (c, d e l) é, possivelmente, outra explicação para os valores percentuais diminuídos na leitura das palavras Cala eDica (Excl. 2). No caso da palavra Lapa (Excl. 3), apresentada a P3, observase a troca das consoantes (l por p), lida como Papa, mostrando que os Ps ainda não estavam sob o controle das consoantes. O n em, quando apresentados próximos, podem ter favorecido a leitura incorreta pela semelhança de suas formas. Por exemplo, a palavra Ana foi lida, também, por P2, como Ama. Já, a palavra Gol (Excl. 8) foi lida como Gole, não havendo o reconhecimento da letral sozinha.

A presença do acento agudo pode ter aumentado a dificuldade de leitura, pois os Ps ainda o desconheciam, por exemplo, com a palavra Boné (Excl. 6). Somente P2 (Conjunto AAA) leu corretamente esta palavra no pósteste, sendo que todos os outros Ps (1, 6 e 7) erraram-na. Já, no Conjunto ABA, a leituraincorreta ocorreu, somente, no pré-teste(por P4). A inversão das sílabas, na leitura da palavra Vaca (Excl. 10), lida como Cava, por P1 (na aplicação da Excl. 10), constituiu-se, também, como uma dificuldade.

A dificuldade encontrada na leitura da palavra de generalização Carro (Excl. 7) deu-se, possivelmente, pela presença do dígrafo $\mathrm{rr}$, sendo lido como Caro. A leitura da palavra Moça (Excl. 8) apresentou como dificuldade a presença do $\zeta$ pois os participantes ainda desconheciam a sílaba ça da palavra Moça, que foi lida como ca, resultando na verbalização da palavra Moca. Observa-se que todos os Ps (3, 4 e 5) do Conjunto ABA leram esta palavra incorretamente e se limitavam a balançar negativamentea cabeça ou manifestavam-severbalmentedizendo: "Não sei".

As palavras Bar (Excl. 6), Temer (Excl. 9) e Cavar (Excl. 10) tornaram-se, provavelmente, difíceis pela presença do $r$ final. Além do que, Temer (Excl. 9) e Cavar (Excl. 10) são verbos eosparticipantestiveram dificuldadenaidentificação de seus significados, ao contrário dos substantivos concretos, onde elas podiam visualizar ou imaginar os seus referentes pictóricos.

Outro fator que pode explicar a leitura incorreta das palavras de generalização foi que elas não faziam parte do vocabulário dos Ps e muitas delas foram, ainda, substantivos abstratos ou verbos, dificultando, assim, sua retenção eleitura. Por exemplo, Lado, Cala, Dica, Parou, Gaga, Pensa (Conjunto AAA); Pisco, Melar, Lei, Temer, Cavar (Conjunto ABA). Seguindo esse raciocínio, Aiello (1995), em sua pesquisa, propõe a avaliação dos comportamentos aprendidos em outros contextos. " por exemplo, avaliar a leitura e escrita do que foi treinado e do que emergiu em tarefas escolares, leitura de cartazes e/ ou propagandas" (p. 167). Ou seja, testar a leitura das palavras de generalização em contextos funcionais para os Ps. Medeiros e colaboradores (1997b) ressaltam a importância das palavras ensinadas estarem relacionadas com o contexto da criança. Leite (1993) inclui neste processo a importância da funcionalidade do ensino que, segundo ele, " ... deve estar relacionado e contextualizado a partir das condições concretas de vida do aluno" (p. 89). A escolha das palavras de generalização poderia se dar a partir de outdoors, cartazes, rótulos, nomes de ônibus, de ruas, praças e outros. Em relação a esse assunto, Kleiman (1993) diz que " ... avisos, letreiros, panfletos, embalagens, contratos, formulários fazem parte do cotidiano do sujeito letrado sem que represente qualquer ameaça à sua autoconfiança” (p. 99).

Há que destacar um aspecto, no mínimo, intrigante, pois o conjunto de palavras ABA, embora fosse mais complexo que o conjunto de palavras AAA, pela sua diversidade, os Ps 3, 4 e 5 (ABA) apresentam melhor desempenho que 0 apresentado pelos Ps 1, 2, 6 e 7 (Conjunto AAA). Observa-se que o número de palavras de generalização do Conjunto ABA foi o dobro do apresentado no Conjunto AAA (60 em ABA - 30 em AAA). Possivelmente, esse fator tenha influenciado 0 desempenho dos Ps do Conjunto ABA, pois a quantidade maior de palavras apresentadas tenha possibilitado um número maior de recombinações corretas do que as realizadas pelos Ps do Conjunto AAA.

Quecontroles, além dosutilizadosnesseestudo, poderiam ser implementados para separar o efeito das tentativas reforçadas sobre as tentativas não reforçadas ou testes de leitura?Possivelmente, aspalavras dos testes deleitura foram influenciadas pelo reforçamento da leitura das palavras de ensino. Na Etapa deEnsino ou Aprendizagem, as tentativas reforçadas seguiram imediatamente as tentativas não 
reforçadas, como descrito no Procedimento. Essa contingência reforçadora, por contigüidade temporal com o teste de leitura, provavelmente, produziu efeitos reforçadores sobre a leitura das palavras de generalização do teste. Umamaneira decontrolar esse efeito seria aumentar a discriminabilidadedas tentativas dostestes deleitura como, por exemplo, adicionando intervalosintertentativas maiores entreas tentativas reforçadas easnão reforçadas, ou mesmo, apresentando ao participante instruções verbais específicas de que essas palavras, mesmo se lidas corretamente, não seriam conseqüenciadas.

Aténesse ponto, foram analisadas e discutidas variáveis do procedimento. Contudo, quando a pesquisa ocorre em situações escolares, como foi o caso do presentetrabalho, há de se considerar, também, que outras variáveis podem terinterferido nosresultados. A motivação presentena relação professor-aluno pode ser uma delas. Viecili (2002) analisa esse contexto e mostra que professores de uma escola da rede pública tratam diferencialmente grupos de alunos repetentes enão repetentes, punindo maiscomportamentos acadêmicos do primeiro grupo do que do segundo. Leite (1993), a esse respeito, observa “ ... quão desastrosas eram as interferências dos professores que puniam ou ridicularizavam as crianças por terem cometido 'erros' ..." (pp. 86-87). Freire (1996), também, referindo-se a essa questão, afirma: "Sem bater fisicamente no educando o professor pode golpeá-lo, impor-lhe desgostos e prejudicálo no processo de sua aprendizagem" (p. 138). Para Tapia e Fita (1999), " ... as mensagens dadas pelo professor ..." (p. 51) exercem semelhante papel.

Outra variável que, também, pode ter influenciado 0 desempenho dos Psé o tempo de permanência na primeira série, refletido na suas idades. Por exemplo, como visto na Tabela 1, a idade deles é bastante diferenciada: quatro (P2, P3, P4 eP7) apresentam-se acima da faixa etária considerada normal para a 1ํㅡㄹie e três (P1, P5 e P6) estariam dentro dessa faixa (7 anos). Mesmo sabendo-se que a idade cronológicaéa quemenos podeinfluenciar no aprendizado escolar, pode-se observar que os Ps mais velhos (P7 - 15 anos e 10 meses e P3 - 9 anos e 8 meses) são os que obtêm os valores percentuais mais baixos nos testes finais. Ou seja, a experiência escolar desses Ps é mais longa e podem estar inseridos, por mais tempo, em um contexto de fracasso e punição. Segundo Melchiori e colaboradores (1992), “ ... a experiência prévia em sala de aula, antes apontada como uma possível fonte de facilitação dos efeitos do procedimento, podeconstituir, ao contrário, um obstáculo" (p. 110). Assim, areprovação freqüentepodeter seconstituído num fator desmotivador para os Ps, pois, além de interferirem na auto-estima, pode também desencadear a saída definitiva da escola, isto é, a evasão escolar. Por exemplo, os Ps 6 e 7 (AAA) foram reprovados mais de uma vez: P6, antes de iniciar o estudo, foi reprovado duas vezes e, no ano da realização da pesquisa (1998), foi novamente reprovado; P7 (AAA) foi reprovado seis vezes. Ainda em relação aosparticipantes, dosquatro com histórico de repetências, apenas um, $\mathrm{P} 5$, apresenta desempenho com porcentagem alta de acertos (acima de $80 \%$ ); os demais, P6, P7 e P3, apresentam, nos testes finais, porcentagem de leitura correta abaixo de 40\%. Como pode ser visto na Tabela 1, éa mãe de P5 que apresenta nível de escolaridade mais alto (5a série completa), embora o pai seja analfabeto. Assim, as variáveis, número de repetências e nível baixo de escolaridade, podem serelacionar com o fraco desempenho dos participantes. P7, cujo desempenho é o mais fraco (porcentagem baixa de acertos tanto das palavras de ensino como das palavras de generalização) entre todos, étambém o participante que foi reprovado seis vezes, além dos pais não terem cursado por completo a 1a série.

O utra variável relevante, presente nas salas de aula, é o uso inadequado, pelos professores, das contingências de reforçamento. É comum chamarem à atenção quando o aluno apresenta comportamentos dispersivos, resultando no fortalecimento eaumento da probabilidade futura desses comportamentos. Além disso, é também comum, nessas circunstâncias, na tentativa de ensinar, ressaltarem o erro e usarem a punição, produzindo, com isso, aversão às atividades acadêmicas e fuga do ambiente escolar. Favorecem, com isso, uma forma de incapacidade percebida pelo aluno a respeito de si, isto é, de que ele não apresenta condição para a aprendizagem. 0 desempenho dos Ps 7 e 3, em sala de aula, pode ilustrar essa situação. P7 desconhecia as vogais e consoantes. P3, por exemplo, era, muitas vezes, ridicularizado pela professora por apresentar letra feia e um caderno desorganizado e sem capricho. Segundo a professora, ele "fazia literalmente uma salada de letras". Por causa disso, era freqüentemente chamado à atenção, pois a professora não conseguia entender o que ele queria escrever. Fini (1998), comentando os trabalhos de Patto (1991), "chama a atenção para os preconceitos como responsáveis pela estigmatização e pela baixa auto-estima" (p 74). Em relação a esse aspecto, afirma Skinner (1974): “ ... a punição excessiva produz uma deficiência mais crítica de reforço positivo e torna a pessoa 'mais vulnerável a uma depressão severa e à desistência' ". Otta (1986), também, referindo-se a esta questão, afirma "... a criança pode aprender, como resultado de repetidos insucessos, que é incapaz de aprender qualquer coisa" (p. 107). Talvez o que tenha acontecido com esses participantes, é que eles foram forçados a desistir de aprender. Freire (1999), um dos mais importantes educadores brasileiros, comenta apropriadamente: "Não há evasão escolar. A palavra evasão é 
puramente ideológica. As crianças são expulsas da escola pelo descaso dos governos, pelo despreparo dos professores e pela ideologia elitista das escolas" (p. 106). No caso desses participantes, haveria a necessidade de um maior e variado número de atividades, tanto acadêmicas, quanto aquelas não diretamente relacionadas ao ensino e que favorecessem o resgate da cidadania, perdido nos inúmeros episódios de fracassos escolares.

O número de repetências e o nível de escolaridade dos pais são outro conjunto de variáveis que podem ter tido algum tipo de influência sobre o desempenho dos Ps. Dos quatro Ps com histórico de repetências, apenas um, P5, apresenta desempenho com porcentagem alta de acertos de leitura generalizada (acima de 80\%), cuja mãe apresenta nível de escolaridade mais alto ( $5^{\text {a }}$ série completa), embora o pai seja analfabeto; os demais, P6, P7 eP3, com duas, sete e duas repetências respectivamente, apresentam, nos testes finais, porcentagem de leitura correta abaixo de 40\%, com 0 nível de escolaridade de seus pais não indo além da $1^{\mathrm{a}}$ série, sendo que os pais de dois deles (de P7 e de P3) nem a $1^{\mathrm{a}}$ sérieterminaram. $\mathrm{O}$ despreparo acadêmico dos paisfrente aos problemas escolares, possivelmente, agravou ainda mais o quadro de dificuldades de aprendizagem. Sobre este assunto, Kleiman (1993) afirma: "Daí que o ciclo de analfabetismo se perpetue num processo que não parece ter fim: geralmente, 0 analfabeto é ele mesmo filho de analfabetos, e, apesar de seus esforços, ele é também pai de analfabetos" (p. 97). Para Witter e Lomônaco (1987), as variáveis familiares podem também influenciar o contexto escolar de ensino-aprendizagem: "especialmente na área da linguagem e pensamento, que são comportamentos complexos do domínio da cognição, fundamentais para 0 aprendizado da leitura e escrita" (1987, p. 75).

Finalmente, poder-seia perguntar: essas crianças não teriam adquirido um padrão decomportamento semelhante a sentir-sedesamparado? Em seu trabalho, Nunes (1990) analisa a relação entre o fracasso escolar e a teoria de Seligman (1975) sobre o desamparo adquirido (helplessness), caracterizado como o desenvolvimento de um traço paralelo à depressão: “ ... Martin Seligman prevê, para indivíduos com repetidas experiências traumáticas (ou não-gratificantes), uma tendênciaa apresentar traços deimpotência efragilidade que caracterizam o desamparo" (citado em Nunes, p. 151). No caso de P7, além do histórico desfavorável, um outro acontecimento podeter influenciado seu estado motivacional: sua mãe faleceu no decorrer no ano letivo provocando, com isso, a perda de seu local fixo de moradia, e tendo que ficar, cada dia, na casa de um parente. A partir daí, desenvolveu-se um quadro com características depressivas.

\section{Considerações Finais}

Ao término deste artigo, não se poderia deixar de explicitar algumas daslimitaçõespresentese daspossibilidades futuras dos procedimentos de equivalência de se tornarem, por seu próprio direito, métodos de alfabetização. Presentemente, os pesquisadores têm, ainda, se deparados com persistente variabilidade nos dados (Matos \& Hübner, 1997; d'Oliveira \& Matos, 1993), tanto intra como inter participantes. A ênfase nos dados obtidos individualmente pode ser considerada uma segunda limitação, pois não tem permitido expandir o conhecimento para contextos mais amplos, principalmente a sala de aula.

Os dados preliminares do trabalho de Piccolo, Porto, Lazarin eGoyos (2002) mostram, em um dos experimentos baseado no experimento realizado por MacDonald, Dixon e LeBlanc (1986), possibilidades para a aprendizagem observacional, formação e expansão de equivalência de estímulosem universitários trabalhando em dupla. Medeiros e colaboradores (1998) mostram, num procedimento coletivo realizado em sala de aula com crianças repetentes de 1a série e num centro religioso, também com crianças repetentes de 1a série(Medeiros \& cols., 1999) possibilidades de expansão do procedimento individual para 0 procedimento coletivo, e também outros tipos de problemas.

Finalizando, pode-se dizer que o conhecimento acumulado ainda não permite aos pesquisadores classificar equivalência de estímulos como um sistema geral para alfabetização, principalmente no contexto de sala de aula, pois o conhecimento produzido tem se limitado quase queexclusivamenteao ensino depalavraspara participantes individuais. Falta à área o desenvolvimento de estudos sistemáticos para o ensino de frases e de textos.

\section{Referências}

Aiello, A. L. R. (1995). Efeitos de um proødimento de resposta construída sobrea rede de relaọões de equivalência envolvida em leitura eescrita em crianças œom história de fracasso escolar. Tese de doutorado não-publicada, Curso de PósGraduação em Psicologia, Área de concentração em Psicologia Experimental, Universidade de São Paulo. São Paulo, SP.

Barros, R. S. (1996). Análise do comportamento: Da contingência de reforço à equivalência de estímulos. Cademo de Textos de Psiologia,1(1), 714.

d'Oliveira, M. H. (1990). Estudos em relaçoes de equivalência: Uma œntribuição à identificação da leitura sob controle de unidades mínimas na aprendizagem de leitura com préescolares. Tese de doutorado não-publicada, Curso de Pós-Graduação em Psicologia, Área de concentração em Psicologia Experimental, Universidade de São Paulo. São Paulo, SP.

d'Oliveira, M. H. \& Matos, M. A. (1993). Controle discriminativo na aquisição da leitura: Efeito da repetição e variação na posição das sílabas e letras. Temas em Psiologia, 2, 99-108. 
de Rose, J. C. C. (1993). Classes de estímulos: Implicações para uma análise comportamental da cognição. Psicologia: Teoria e Pesquisa, 9(2), 283-303.

de Rose, J. C. C., Souza D. G., Rossito, A. L. \& de Rose, T. M. S. (1989). Aquisição de leitura após história de fracasso escolar: Equivalência de estímulos e generalização. Psioologia: Teoria e Peequisa, 5(3), 325-346.

de Rose, J. C. C., Souza, D. G., Rossito, A. L. \& de Rose, T. M. S. (1992). Stimulus equivalence and generalization in reading after matching to sample by exclusion. Em S. C. Hayes \& L. P. Hayes (Orgs.), Understanding verbal relations (pp. 69-82). Reno, EUA: Context Press.

Dixon, L. S. (1977). The nature of control by spoken words over visual stimulus selection. Journal of the Experimental Analysis of Behavior, 27, 433-442.

Fini, L. D. T. (1998). Rendimento escolar e psicopedagogia. Em F. F. Sisto, G. C. Oliveira, L. D. T. Fini, M. T. C. C. Souza \& R. P. Brenelli (Orgs.), Atuação psiopedagógica e aprendizagem esolar (p. 74). Petrópolis: Vozes.

Freire, P. (1985). Pedagogia do oprimido (14를. ed.). Rio de Janeiro: Paz e Terra. (Original publicado em 1978)

Freire, P. (1996). Pedagogia da autonomia: Saberes neecesários à prática educativa. São Paulo: Paz e Terra.

Freire, P. (1999, 29 de dezembro). Paulo Freire. Isto É, 1578, 106 (Edição especial: 100 fatos que marcaram o século).

Hanna, E. S., Souza, D. G., de Rose, J. C., Santos, L. G., Fonseca, M. L., Horowitz, D. B., Carvalho, G. P., Sallorenzo, L. H., Balduino, L. H. \& Veiga, H. (1993). Treino de cópia com resposta construída e o desempenho em ditado II: Efeitos dependentes do nível de generalização na linha de base de leitura [Resumos]. Em Sociedade Brasileira de Psicologia (Org.), Resumos de cmunicaũoes científicas, XXV Reunião Anual de Psioologia (p. 305). Ribeirão Preto: SBP.

Hübner, M. M. (1997). O paradigma de equivalência e suas implicações para a compreensão e emergência de repertórios complexos. Em R. A. Banaco (Org.), Sobrecomportamento ecognição: Aspectosteórios, metodológioøs edeformação em análisedo comportamento e terapia cognitivista (pp. 423-430). São Paulo: ARBytes.

Kleiman, A. B. (1993). Exclusão social e alfabetização. Temas em Psiølogia, 3, 97- 107.

Leite, S. A. S. (1993). Alfabetização escolar: Repensando uma prática. Temas em Psicologia, 3, 85-95.

MacDonald, R. B. F., Dixon, L. S. \& LeBlanc, J. M. (1986). Stimulus class formation following observational learning. Analysis and Intervention in Developmental Disabilities, 6, 73-87.

Mackay, H. A. (1985). Stimulus equivalence in rudimentary reading and spelling. Analysis and Intervention in Developmental Disabilities, 5, 373-387.

Matos, M. A. \& Hübner, M. M. (1997). Oralização é cópia: Efeitos sobre a aquisição de leitura generalizada recombinativa. Temas em Psiologia, 1, 47-63.

Matos, M. A., Hübner, M. M. \& Peres, W. (1997). Leitura generalizada: Procedimentos e resultados. Em R. A. Banaco (Org.), Sobre comportamento ecognição: Aspectosteórios, metodológicosedeformação em análisedo œmportamento e terapia cognitivista (p. 471). São Paulo: ARBytes.

Medeiros, J. G., Antonakopoulu, A., Amorim, K. \& Righetto, A. C. (1997a). O uso da discriminação condicional no ensino da leitura e escrita. Temas em Psiologia, 1, 23-32.

Medeiros, J. G., Monteiro, G. \& Silva, K. Z. (1997b). O ensino da leitura e escrita a um sujeito adulto. Temas em Psioologia, 1, 65-78.

Medeiros, J. G., Jacomino, A. P., Santos, M., Bittelbrunn, E. A. K., Antonakopoulu, A., Monteiro, G. \& Rössel, A. (1998). Novas estratégias para o ensino da leitura e escrita: 0 uso da discriminação condicional em situação coletiva. [Resumos]. Em Sociedade Brasileira de Psicologia (Org.), Resumosdecomunicaọoescientíficas, XXVIII Reunião Anual dePsiølogia (p.21). Ribeirão Preto, SP: SBP.

Medeiros, J. G., Rössel, A., Wendt, N. C., Silva, P. M., Amorim, K., Bittelbrunn, E. \& Antonakopoulu, A. (1999). A aquisição da leitura e escrita num contexto experimental coletivo e possíveis generalizações para 0 contexto da sala de aula. [Resumos]. Em Sociedade Brasileira de Psicologia (Org.), Resumos de cmunicaõoes científicas, XXIX Reunião Anual de Psiologia (pp.78-79). Campinas, SP, SBP.
Melchiori, L. E., Souza, D. G. \& de Rose, J. C. C. (1992). Aprendizagem de leitura por meio de um procedimento de discriminação sem erros (exclusão): Uma replicação com préescolares. Psiologia: Teoria e Pesquisa, 8(1) 101-111.

Nunes, A. N. de A. (1990). Fracasso escolar e desamparo adquirido. Psiologia: Teoria e Pesquisa, 6(2), 139-154.

Otta, E. (1986). Motivação. Psiølogia no ensino de $2^{\circ}$ grau: Uma proposta emandipadora. São Paulo: Edicon.

Patto, M. H. de S. (1991). A produção do fracasso esolar. São Paulo: T.A. Queiroz.

Piccolo, A. A. T., Porto G., Lazarin, T. C. \& Goyos, C. (2002). Aprendizagem observacional de discriminações condicionais, formação e expansão de dasses de equivalência em préescolares [Resumos]. Em Sociedade Brasileira de Psicologia (Org.), Resumos de comunicações científicas, XXXII Reunião Anual de Psicologia (pp. 84-85). Florianópolis, SC: SBP.

Seligman, M. (1975). Helplessess. San Francisco: W. H. Freeman.

Sidman, M. (1971). Reading and auditory-visual equivalencies. Journal of Speech and Hearing Research, 14, 5-13.

Sidman, M. (1986). Functional analysis of emergent verbal classes. Em T. Thompson \& M. D. Zeiler (Orgs.), Analysis and Integration of Behavioral Units (pp. 213-245). Hillsdale, N. J.: Erlbaum.

Sidman, M. (1990). Equivalence relations: Where do they come from? Em D. E. Blackman \& H. Lejeune (Orgs.), Behaviour analysis in theory and practice Contributions and ontroversies Brighton, U.K.: Erlbaum.

Sidman, M. (1994). Equivalenœ relations and behavior: A research story. Boston: Authors Cooperative.

Sidman, M. \& Cresson, O. (1973). Reading and crossmodal transfer of stimulus equivalencies in severe mental retardation. American Journal of Mental Deficiency, 77, 515-523.

Sidman, M. \& Tailby, W. (1982). Conditional discrimination vs. matching to sample: An expansion of the testing paradigm. Journal of the Experimental Analysis of Behavior, 37(1) 15-22.

Skinner, B. F. (1974). Sobre o behaviorismo. (M. P. Villalobos, Trad.). São Paulo: Cultrix.

Silva, R. M. F., Medeiros, J. G. \& Souza, M. (2001). Equivalência de estímulos: Uma nova metodologia que possibilita minimizar as dificuldades de aprendizagem na leitura escrita [Resumos]. Em Sociedade Brasileira de Psicologia (Org.), Resumos de comunicaọões científicas, XXXI Reunião Anual de Psiologia (pp. 124-125). Rio de Janeiro, RJ: SBP.

Souza, D. G. \& de Rose, J. C. C. (1992). Generalized reading: Acquisition of stimulus control by minimal textual units [Trabalho completo]. Em American Psychological Association, Anais da XVIII Convenção Anual da Association for Behavior Analysis. San Francisco, EUA: APA

Souza, D. G. \& de Rose, J. C. (1997). Transferência de controle de estímulos de figuras para texto no desenvolvimento de leitura generalizada. Temas em Psioologia, 1, 33-46.

Staats, A. W., Staats, C. K., Schutz, R. E. \& Wolfe, M. (1962). The conditioning of textual responses using "extrinsic reinforcers". Journal of the Experimental Analysis of Behavior, 5, 33-40.

Tapia, J. A. \& Fita, C. E. (1999). A motivação em sala deaula: 0 queé, œmo æe faz. São Paulo: Loyola.

Viecili, J. (2002). A œerção em sala de aula: Decorrências de seu uso na produção do fracasso esolar. Dissertação de Mestrado não-publicada, Programa de Pós-Graduação em Psicologia, Curso de Mestrado, Universidade Federal de Santa Catarina. Florianópolis, SC.

Witter, G. P. \& Lomônaco, J. F. (1987). Psioologia da aprendizagem: Aplicaọoes na esola. São Paulo: EPU.
Recebido: 01/08/2001

1ํ. Revisão: $14 / 11 / 2001$

Última Revisão: 03/06/2002

Aœite Final: 07/06/2002 
Sobre os autores

José Gonçalves Medeiros éDoutor em Psicologia Experimental pela UniversidadedeSão Paulo, pesquisador-bolsista do CNPq e Professor do Programa de Pós-graduação em Psicologia da UniversidadeFederal deSanta Catarina.

Rosária Maria Fernandes da Silva éMestrepelo Programa dePós-graudação em Psicologia da Universidade Federal de Santa Catarina. É Professora do curso dePsicologia da Fundação

Universidade do Vale do Itajaí. 